\title{
Looking at the Heart of Patients with Chronic Obstructive Pulmonary Disease
}

\author{
José Luis Izquierdo \\ Servicio de Neumología, Hospital Universitario de Guadalajara, Guadalajara, Spain
}

Chronic obstructive pulmonary disease (COPD) is a first-magnitude health problem due to its high morbidity, mortality and socioeconomic burden. Several studies have reported that patients with COPD have a high prevalence of associated diseases, such as cancer and cardiovascular diseases, which are particularly frequent [1]. In the study by Divo et al. [2], the authors followed up 1,664 COPD patients over 51 months and assessed the impact of 79 comorbidities. They confirmed that comorbidities play an important role in COPD, and the most critical finding was that 12 of them negatively influenced survival. Certainly, appropriate intervention will favorably affect the patient's well-being and reduce the risk of death. Supporting these observations, it is interesting to highlight the Copenhagen study results from the perspective of the GOLD 2011 classification [3]. In this study, COPD mortality was higher in patients with stage $B$ than in those with stage C COPD, the latter having a poorer lung function. However, the level of comorbidity of ischemic heart disease and cardiovascular disease was higher in stage $B$ COPD, which presumably influenced the mortality rate of these patients. In fact, large clinical trials have shown that while in patients with severe and very severe disease death is determined by the respiratory disease, in patients with mild to moderate disease, cancer and cardiovascular diseases are the most frequent causes of death. In patients with moderate COPD, $16.8 \%$ of deaths were related to respiratory and $14.4 \%$ to cardiovascular events in the UPLIFT trial, and $28 \%$ of deaths were related to cardiac and only $4 \%$ to respiratory events in the TORCH trial. These findings have emphasized the role of cardiovascular diseases in the clinical status and mortality rate of patients with COPD [4-6].

In the last decade, it was suggested that COPD could favor the onset of ischemic heart disease. Although patients with COPD have more cardiovascular complications than people without COPD ( 12.5 vs. $4.7 \%$ in a casecontrol study) [7], there are currently not enough data to establish a causal link between COPD and cardiovascular disease. The concept of systemic inflammation as a common pathogenic mechanism has not been clearly proven, and this increased risk could be justified largely by a higher prevalence of traditional risk factors [8]. Therefore, the essential question that still remains is whether this comorbidity is produced by COPD itself, by common risk factors or whether it is a mere coincidence of highly prevalent processes in patients of advanced age. However, whether there is a causal relationship or whether they are coincident diseases, it remains clear that an increased prevalence of diseases associated with COPD not only increases the complexity and the economic burden of the diseases, but they are also predictors of mortality, so we must demand an extra effort to identify them and establish a comprehensive treatment for the patients [9].

\section{KARGER 125}

(c) 2015 S. Karger AG, Base

0025-7931/15/0903-0187\$39.50/0
José Luis Izquierdo

Servicio de Neumología

Hospital Universitario de Guadalajara

C/Donante de sangre sn, ES-19002 Guadalajara (Spain)

E-Mail jlizquierdo@ sescam.org 
In this issue of Respiration, Ahn et al. [10] analyze 229 patients with COPD confirmed by post-bronchodilator spirometry, evaluated retrospectively from a sample of 5,207 patients referred to a tertiary pulmonologist and cardiologist clinic. Other confounding diseases such as bronchiectasis or residual tuberculosis lesions were excluded. Similarly to other studies, after a follow-up of 6.48 \pm 4.09 years, in this population with mainly moderate airflow limitation $\left(\mathrm{FEV}_{1} \% 63.7 \pm 18.6\right)$, mortality was most frequently due to heart failure (20.5\%), while respiratory failure due to acute exacerbation of COPD occurred only in $14.1 \%$. In the multivariate Cox regression analysis, besides $\mathrm{FEV}_{1}$ (a well-known predictor of mortality), a lower left ventricular ejection fraction and a lower hemoglobin level were independent risk factors for a higher mortality rate in COPD patients.
As the authors pointed out, this study has several limitations and can be considered as a hypothesis-generating study. Because of the retrospective design and a clear bias selection, their conclusions must not be extrapolated to a general population of patients with COPD. In fact, the high prevalence of coronary artery disease $(59.4 \%)$ is disproportionate when we compare their prevalence in large clinical trials or in other observational studies. It is clear that we need comprehensive information from well-designed prospective studies with enough follow-up periods. In the meantime, the results of this study should alert the clinician to the role of cardiovascular comorbidities in COPD patients, since taking them into consideration could improve the symptoms and survival in many patients that live and die with COPD but not for COPD.

\section{References}

$\checkmark 1$ Smith MC, Wrobel JP: Epidemiology and clinical impact of major comorbidities in patients with COPD. Int J Chron Obstruct Pulmon Dis 2014;9:871-888.

2 Divo M, Cote C, Juan P, de Torres JP, et al: Comorbidities and risk of mortality in patients with chronic obstructive pulmonary disease. Am J Respir Crit Care Med 2012;186: 155-161.

-3 Lange P, Marott JL, Vestbo J, Olsen KR, Ingebrigtsen TS, Dahl M, Nordestgaard BG: Prediction of the clinical course of chronic obstructive pulmonary disease, using the new GOLD classification: a study of the general population. Am J Respir Crit Care Med 2012; 186:975-981.
4 Anthonisen NR, Melissa A, Skeans MS, Wise MD, Manfreda J, et al: The effects of a smoking cessation intervention on 14.5-year mortality. Ann Intern Med 2005;142:233-239.

5 McGarvey LP, Magder S, Burkhart D, et al: Cause-specific mortality adjudication in the UPLIFT $^{\circledR}$ COPD trial: findings and recommendations. Respir Med 2012;106:515-521.

-6 McGarvey LP, John M, Anderson JA, Zvarich M, Wise RA: Ascertainment of cause-specific mortality in COPD: operations of the TORCH Clinical Endpoint Committee. Thorax 2007; 62:411-415.

7 de Lucas-Ramos P, Izquierdo-Alonso JL, Rodriguez-Gonzalez Moro JM, Frances JF, Lozano PV, Bellón-Cano JM; CONSISTE study group: Chronic obstructive pulmonary disease as a cardiovascular risk factor. Results of a case-control study (CONSISTE study). Int J Chron Obstruct Pulmon Dis 2012;7:679-686.
8 Yusuf S, Hawken S, Ounpuu S, et al: Effect of potentially modifiable risk factors associated with myocardial infarction in 52 countries (the INTERHEART study): case-control study. Lancet 2004;364:937-952.

9 Barr RG, Celli BR, Mannino DM, Petty T, Rennard SI, Sciurba FC, et al: Comorbidities, patient knowledge, and disease management in a national sample of patients with COPD. Am J Med 2009;122:348-355.

10 Ahn Y-H, Lee KS, Park JH, et al: Independent risk factors for mortality in patients with chronic obstructive pulmonary disease who undergo comprehensive cardiac evaluations. Respiration 2015;90:199-205. 